\title{
INTRODUCTION
}

The present volume contains papers delivered in the twenty-seventh, twentyeighth, and twenty-ninth annual Lecture Series (1986-1989) sponsored by the University of Pittsburgh's Center for the Philosophy of Science. The authors will be immediately recognized as among the leading lights in current philosophy of science. Thus, taken together, the papers provide a good sample of work being done at the frontiers of research in philosophy of science. They illustrate both the contemporary reassessment of our philosophical heritages and also the opening of new directions of investigation. The brief remarks that follow cannot hope to do justice to the rich and rewarding fare to be found herein but are supposed to serve only as a menu.

\section{INFERENCE AND METHOD}

Students in philosophy of science used to be taught to respect the distinction between "the context of discovery" and "the context of justification." The philosophy of science (so the story went) is concerned with the latter context but not the former. It seeks to provide principles for evaluating scientific hypotheses and theories once they are formulated, but it must remain modestly silent about the process of discovery since hypotheses and theories are free creations of the human mind and since the creative process is the stuff of psychology, not philosophy. The discovery/justification distinction is now under pressure from several directions, one of which stems from work in artificial intelligence and formal learning theory. Granted that scientists do in fact arrive at theories by a process of guesswork, intuition, or whatever, it remains to ask what true theories can be reliably discovered by what procedures. More specifically, for a specified kind of theory and a specified class of possible 
worlds, does there exist a procedure (recursive or otherwise) such that for every possible evidence sequence from any of the possible worlds the procedure eventually finds every true theory of the given type and eventually avoids every false theory of the given type? In their contribution, Clark Glymour and Kevin Kelly show how to make such questions precise, and for some precise versions they provide precise answers. But as they note, a host of such questions remain begging for further investigation.

Jaakko Hintikka's contribution draws out some of the implications for induction of his interrogative model of inquiry. This model conceptualizes scientific inquiry as a game played by a scientist against Nature. The scientist's goal is to derive a conclusion $\mathrm{C}$ from a starting premise $\mathrm{P}$. To reach this goal, the scientist is allowed two kinds of moves: an interrogative move in which a question is put to Nature and an answer received, and a deductive move in which he draws logical consequences from $P$ and the answers received to interrogative moves. A very striking feature of this model is the absence of any place for induction as it is traditionally conceived. Hintikka argues that Hume's classic problem of induction is an artifact of the mistaken assumption that the only answers Nature gives to queries are in the form of atomic (i.e., quantifierfree) sentences. Hintikka sides with the view, traceable to Newton and beyond Newton to Aristotle, that observation and experiment provide us with propositions that possess a significant generality. The residual, non-Humean problem of induction, as Hintikka conceives it, consists in extending the scopes of and unifying the general truths received from Nature.

According to the textbooks, modern science eschews Aristotelian natures in favor of laws of nature construed as codifications of regularities. In her provocative contribution Nancy Cartwright contends that this common wisdom is flawed, for in her view laws of nature are about natures. Thus, for Cartwright, Newton's law of gravitation doesn't say what forces bodies actually experience but rather what forces it is their nature, as massive objects, to experience. The exceptionless regularities required by the empiricist account are rarely found, she contends, and where they are found they result from arrangements that allow stable natures to be manifested. Cartwright supports her neo-Aristotelian conception of laws by arguing that it makes more sense of experimental methodology and inductive procedures than the more popular empiricist view.

If empiricism is the view that no matter of fact can be known a priori, then Hume was not an empiricist. For, as Barbara and Gerald Massey show in their contribution, Hume's account of animals attributes to them factual knowledge which is not learned from experience but which is imparted to them by "the original hand of Nature." Hume could be said to remain an empiricist insofar as he denies that human beings have specialized innate cognitive faculties or instincts as opposed to generalized instincts, such as the inductive propensity. But the distinction between specialized and generalized propensities is vague and, thus, the boundaries of empiricism are fuzzy. If Nelson Goodman is right, 
we are endowed with the propensity to project 'green' instead of 'grue.' And Noam Chomsky has championed the view that we are endowed with complex propensities to map linguistic evidence to linguistic knowledge. Do such propensities, which are at once special and general, lie inside or outside the boundaries of empiricism?

Logical positivism is a failed program. But its real shortcomings are quite different from those besetting the caricatures that dot the potted histories of philosophy. For example, the leading logical positivists (apart from Schlick) did not subscribe to the naive empiricism of a neutral observation language; indeed, as Michael Friedman notes in his contribution, the theory-ladenness of observation was explicitly emphasized by Carnap and others. Friedman argues that the ultimate shortcoming of positivism as embodied, say, in Carnap's Logical Syntax of Langunge lay in its failure to establish a neutral framework from which alternative languages or frameworks could be judged. Friedman traces this failure to Gödel's incompleteness theorems and argues that the demise of Carnap's program does not promote relativism - as expressed by a notion of truth relativized to a framework-but pulls the rug out from under this and other fashionable relativisms.

If asked to list the most important accomplishments of twentieth-century philosophy, the majority of the profession would surely give prominent place to Quine's slaying of one of two dogmas of empiricism--the existence of the analytic-synthetic distinction (that is, a principled distinction between truths of meaning and truths of fact). This accomplishment would not appear on Noam Chomsky's list. Indeed, in his paper for this volume, Chomsky argues that Quine's result is, ironically, an artifact of an overly behavioristic and a too narrowly positivistic conception of how the scientific investigation of language should and does proceed. In particular, he claims that the strictures imposed by Quine's paradigm of "radical translation" are not accepted in and would undermine the process of inquiry in the natural sciences.

\section{THEORIES AND EXPLANATION}

The theories of modern science tell stories of unobservable entities and processes. Scientific realists contend that these stories are not to be read as fairy tales and that observational and experimental evidence favorable to a theory is to be taken as evidence that the theory gives us a literally true picture of the world. Richard Boyd, one of the leading exponents of scientific realism, has in the past been concerned to combat the logical empiricists and their heirs who (with some notable exceptions such as Hans Reichenbach) contend that scientific theories are to be read instrumentally or else that we are never warranted in accepting a theory except as being adequate to saving the phenomena. Here Boyd is concerned with the more elusive and insidious opponent of realism who contends that the very notion of "the world" to which theories can 
succeed or fail in corresponding is a delusion since science is the social construction of reality. Some forms of constructivism have been successfully answered; for example, those that take their cue from Kuhnian incommensurability can be rejected on the basis of a causal theory of reference. Other more subtle forms of constructivism remain to be answered. Boyd's contribution is aimed at identifying the most interesting of these forms and showing that the "philosophical package" in which they come wrapped cannot be reconciled with the content and procedures of science.

Diderik Batens gives a resounding "No" to his query "Do We Need a Hierarchical Model of Science?" In place of both hierarchical and holistic models he proposes a contextualistic approach in which problems are always formulated and attacked with respect to a localized problem-solving situation rather than with respect to the full-knowledge situation. On Batens's account, methodological rules as well as empirical assertions are contextual. This has the interesting consequence that no a priori arguments can demonstrate the superiority of science to astrology; rather the superiority has to be shown on a case-by-case basis in a range of concrete problem-solving contexts.

What was once the "received view" of scientific theories, which emphasized the representation of scientific theories as a logically closed set of sentences (usually in a first-order language), has given way to a "semantic" or "structuralist" view, expounded in different versions by Patrick Suppes, Joseph Sneed, Fredrick Suppe, Bas van Fraassen, and others. But what exactly is the difference between these two ways of understanding theories? And what exactly was wrong with or lacking in the older view? In his contribution Richard Grandy argues that the proponents of the semantic view are offering not so much a new account of theories per se as a new account of the epistemology and application of theories. In his contribution Sneed responds to critics who charge that the semantic-structuralist reconstructions of theories are inadequate because they fail to provide syntactic representations of crucial items. By providing syntactic formulations of "lawlikeness," "theoretical concepts," and "constraints," Sneed paves the way for a reconciliation of the old and new views of theories, and at the same time he opens up a new avenue of research by connecting his structuralist account with previous work on data bases.

In his contribution Hilary Putnam explains why he has abandoned a view he helped to articulate and popularize - the computational or functional characterization of the mental. He continues to hold that mental states cannot be straightforwardly identified with physical states of the brain. But he now proposes to turn the tables on his former self by extending his own arguments, previously deployed to show that "software" is more important than "hardware," to show that mental states are not straightforwardly identical with computational states of the brain. What does Putnam propose as a replacement for functionalism? Some hints are to be found in the present paper and in his book Representation and Reality (Cambridge, Mass.: MIT Press, 1988), 
but for a complete answer the reader will have to stay tuned for further developments.

Hartry Field is more sanguine about another major "ism"-physicalism. He tries to chart a course between the Scylla of formulating the doctrine in such a strong form as to make it wholly implausible and the Charybdis of making it so weak as to have no methodological bite. The form of physicalism that Field takes to be worthy of respect is along the lines of reductionism, asserting (very roughly) that all good explanation must be reducible to physical explanation. He argues that weaker versions of physicalism, such as supervenience, that lack the explanatory requirement founder on the Charybdis. What remains to be specified to make physicalism a definite thesis is the reduction base: what are the considerations in virtue of which a science or a theory is properly classified as being part of physics?

John Earman

University of Pittsburgh 
